\title{
Learning and teaching across borders: How pedagogical partnership and international schooling shaped me personally and determined my future career direction
}

\author{
Polina Vandysheva, Centre for English and Additional Languages (CEAL), Lingnan University \\ Hong Kong, Hong Kong.
}

Contact: polinavandysheva@ln.hk

Studying in three completely different countries and serving as a student partner in a faculty-student pedagogical partnership program has given me valuable insights into different approaches to teaching and learning and has unexpectedly changed my direction in life. In this reflective piece, I would like to share my experiences with varied international educational approaches and the transformative potential of partnering with faculty. I will also discuss how learning experiences may be enhanced by partnership approaches in my home country, where this kind of collaboration is traditionally lacking.

\section{MY LEARNING EXPERIENCES ACROSS BORDERS}

People between the ages of 6-23 spend the majority of their time on education, thus it is right to assume that the way people are taught has a great effect on their emotional and mental development, their personality, and ultimately, their career choices. As I was born and raised in Russia, my initial schooling was conducted very authoritatively. The majority of teachers were not open to any feedback, teaching students with the use of a common expression: "The teacher is always right." This might be attributed to the conservative upbringing and education of Russian teachers, which emphasizes the undeniable authority of older, more experienced people.

Unfortunately, in my experience, this kind of approach diminishes students' interest in schooling and sets a negative attitude towards further education. Despite my secondary school having elite status, it used very outdated pedagogical methods and learning materials. Students could not communicate their opinions to the teachers, who would often show their dominance in the classroom by raising their voices and criticizing students in a judgmental manner, rather than giving affirmation or encouragement, thereby creating an unreasonably and unnecessarily stressful environment. As an example, any time a student could not answer a math equation quickly enough, the teachers would call us "blind, deaf, but not mute," and instead of helping us, would scold us and give the student an " $F$ " for that lesson. For me, this approach led to a lack of motivation to study, excessive cheating, and constant fear of failure. I questioned my intellectual capabilities, my competence, and my ability to succeed in life. This put huge constraints on my self-esteem and my aspirations and created a feeling of resentfulness towards the whole education process. A feeling of alienation and lack of belonging led me to question, what was the point of education? 
Seeking a different kind of education environment, I decided to apply to a private school in the United States for my final two years of high school. In America, my perception of education drastically changed. A less hierarchical, democratic environment with a different mentality regarding relationships between teachers and students causes the U.S. to have a much more liberal approach towards education. On the whole, teachers are very approachable, more involved in students' lives, and open to communication.

The teachers that I had were the most caring and engaged people that I had ever met in my life up to that point. I felt comfortable in the classroom despite my initial challenges with the language. Their up-to-date teaching approach, non-judgemental attitude, and openness to dialogue restored my curiosity for learning. For instance, instead of scolding students for wrong answers, as in Russia, teachers would ask follow-up questions, leading students to the correct answer. Teachers were also supportive about oncampus activities, both academic and non-academic, and often took the initiative to lead or be active alongside the students. It was common to have lunches together and build personal relationships. These interpersonal dynamics allowed me to get over my fear of failure, join a variety of extracurricular activities, and to participate in and eventually become a champion in the Southern California Academic Decathlon. Throughout the whole time, I felt constant support and encouragement from my teachers, resulting in an empowering environment.

I then received a full scholarship for undergraduate studies at Lingnan University Hong Kong-a place where they say East meets West. Hong Kong still has strong conservative values as part of Chinese culture, but it is also adapted to a range of liberal beliefs and principles due to its colonial background and international exposure. It should be an ideal place for the implementation of progressive ideas and solutions in the education field. Incidentally, this was also the reasoning behind the first pedagogical Student Consultant Program being started in Hong Kong (Pounder et al., 2016).

Lingnan University has a multicultural mix of overseas and local academic staff, many of whom have had international exposure. This provides the university with modern ways of teaching, including the implementation of technology in creative and interactive ways. I observed that some faculty are eager to continually fine-tune their teaching. They voluntarily attend professional development programs, are willing to hear students' perspectives on their teaching, and actively seek out more creative ways to teach and inspire their students. On the other hand, I also came across more conservative professors that use demotivational, old-school methods of teaching; interact little with students; emphasize strict discipline in the classroom; and seem to be content to teach the same way year after year. Throughout my 4 years, I experienced various teaching styles and approaches of different professors. This might not be an uncommon situation in academia, but to me, already having educational experiences in two different extremes, the contrast seemed obvious.

\section{MY PARTNERSHIP EXPERIENCE}

Seeing these differences in teaching methods and the untapped potential of some professors made me think about ways I could improve the learning experience and environment at the university, for both the students and professors. In my second year, I was invited to join the Faculty-Student Partnership Program (FSPP) ${ }^{1}$. The program helps to build bridges between students and faculty members at Lingnan University, improve teaching and learning in the classroom, and help students better achieve the learning 
outcomes. As in other student consultant-type programs, student partners are assigned to faculty partners and do teaching observations, write detailed reports, and have regular meetings with their faculty partners. Every semester, student partners are paired with a different faculty member from a different discipline to expose us to a variety of teaching styles and methods. Throughout the program, I have partnered with four different professors.

At first, I was certain that professors would not be interested in listening to my opinion as a student on their teaching and would be even less interested in making any changes. However, to my surprise, professors would genuinely listen to my observation of their teaching and point out that they had been anticipating the points covered in the reports. In every partnership, the first meeting was focused on more general comments with a polite tone. However, as the partnership progressed, and the relationship between my faculty partner and myself would reach the level of trust, the reports would get more detailed and straight to the point.

This taught me skills that I had not anticipated learning when I first joined the program. The most important is tactful communication, which I believe will be very useful in my future career. Furthermore, bilateral thinking gave me an insight into the teaching profession and its challenges. This program taught me a lot about what it means to be a good teacher, to consider both sides, and to effectively deliver material.

Surprisingly enough, faculty members who were the most interested in participating in the FSPP, on the whole, were those who already had an above-average performance. The professors I have worked with were highly committed to improving their teaching performance even before joining the program. They had already mastered a lot of aspects when it came to content delivery, presentation skills, and student learning resources. Thus, the scope of the issues faced during the classes by both my faculty partners and students probably reflected only the tip of the iceberg, compared with other faculty who may have needed more help but seemingly had no intention of joining such programs or working on improving their teaching. One question that puzzled me was how to get those teachers that really need help to join teaching enhancement programs. Perhaps the university making such programs mandatory may help more faculty to realize the benefits of faculty-student partnership.

\section{COMMON ISSUES, OUR SOLUTIONS, AND THE RESPONSES}

Some of the issues that faculty and students in Hong Kong come across might be unique compared to other parts of the world. It is important to mention that the medium of instruction of higher education in Hong Kong is English, which becomes a serious challenge for a lot of students since most of their secondary school studies were conducted in Chinese. When faced with foreign professors, in particular, students may have difficulties understanding their accents or keeping up with their speaking pace. For that, I have suggested professors implement various techniques, such as controlling the teaching pace and speaking speed, highlighting keywords both verbally and visually, and supplementing lectures with various kinds of visual and animated support.

Another important issue that was faced by professors is low class participation. This might be attributed to students' language barrier or their cultural or educational background-for instance, students who attend school in Hong Kong are used to more written work and less interactive activities than in America. Thus, it was very important to find an approach most suitable for local students. We have tried a variety of different 
methods, but students were most responsive to written activities (i.e., handouts and cue cards), or activities conducted online (i.e., online quizzes, polls, Kahoot, Mentimeter, etc). Students became more open to new teaching approaches after professors built trust with them, in particular by verbally encouraging them when they participated and by fostering classroom dialogue.

The last issue is related to the content of the lectures. Professors tend to overpack their lectures with theoretical material that is hard to digest for students in one go, especially for non-native English speakers. Consequently, this leads to students losing attention towards the middle of the class. My suggestion was to structure materials in clusters separated by interactive activities, including quick quizzes, videos, and group work. Moreover, it is very important to link the content of the lectures with everyday life and show students a practical approach to what they are learning in class. For this, I have also suggested professors use more relevant examples (depending on the region and subject) with practical activities and personalise their lectures by sharing their own experiences. Notably, students in Hong Kong tend to pay close attention during personal sharing when it is relevant to the material.

Working with my faculty partners throughout each semester, I could start seeing definite changes in their delivery styles and students' receptiveness. Professors would better understand students' needs and become more aware of the difficulties faced by them. More students were attending, paying attention, and participating in the lectures. In general, students would seem more interested in the subject, have more confidence to participate in the discussions, and be more open towards learning the new content.

\section{HOW THE PROGRAM SHAPED ME PERSONALLY AND MY FUTURE CAREER DIRECTION}

Despite an unexpected change in roles, where faculty and student partners relate as equals and learn from each other, through the program, my learned ability to communicate with people with a higher status allowed me to become a competent student partner. I have gained more confidence both inside and outside of the classroom and became more capable of constructively expressing my ideas and opinions. This role has also given me the ability to learn more about the dynamics between faculty and students and develop close relationships with some professors. Furthermore, it enriched my own academic experience at the university and provided me with more opportunities to develop career-related skills, such as critical thinking and attention to relevant details.

After working closely with faculty partners and witnessing the educational process from a student partner's perspective, I have decided to further my education and pursue an academic career. Before joining this program I had never thought about dedicating my life to education or becoming a teacher, but now it is obvious to me that this is something I want to pursue in the future. In America, I had seen how a good teacher could change someone's life - I had a teacher who was passionate about teaching and who also genuinely cared about his students, being like a big brother to us. He helped changed my whole perspective on education. Then, my involvement in the FSPP made me think about what methods I could use to teach students with the hope of making a difference in their lives in the same way my teacher and the partnership program at Lingnan had.

\section{HOW CAN PARTNERSHIP BE IMPLEMENTED IN COUNTRIES SUCH AS RUSSIA?}

In my future career, I would definitely like to implement or be involved in a similar partnership practice myself. In my classes, I would also try to initiate more conversations 
with students in general and get more direct feedback from them. I believe that communication between faculty and students is a key factor to understanding the needs and expectations of students, and that's what makes a learning experience enjoyable and fruitful. These thoughts bring me to consider the situation in Russia.

Ideally, pedagogical faculty-student partnership as a Students-as-Partners (SaP) practice should be implemented internationally. To date, SaP practices have proliferated mainly in the "Global North" (North America, Europe, Australasia, and some developed parts of East Asia [Bindra et al., 2018]). In the Russian system, where the majority of students are not satisfied with the quality of their education, it would be an ideal program to implement. However, despite their practicality and beneficial outcomes, pedagogical partnership programs cannot simply be transplanted into any institution or region without first considering the prevailing cultural and educational context.

This is especially true for a country like Russia, with a very hierarchical system and a prominent power gap. This is not necessarily conducive to facilitating productive facultystudent relationships, which are based around respectful, mutual dialogue. Such relationships are at the core of SaP practices. This is the major challenge I would see in implementing any SaP practice in such a context. Two of Matthews' (2017) "Five Propositions for Genuine Students as Partners Practice" are especially relevant here: to "nurture power-sharing relationships through dialogue and reflection" (\#2, and to "enact partnership for transformation" (\#5) (p. 2). This transformation is not just aimed at the individual level, but at the partnership level, "so that SaP can transform learning relationships toward egalitarian learning communities instead of reproducing existing hierarchies that distance learners and teachers" (p. 6).

However, some minor changes could be implemented by interested teachers or institutions to start changing the educational culture step by step. Currently, it would be most feasible to implement these changes at elite Russian private schools, where teachers with diverse educational backgrounds and higher salaries would have broader experience and a higher incentive to build closer relationships with students. The new approach could eventually be shared more widely during "open days" at selected schools attended by education committee members, teachers, and parents, as well as at regular pedagogical seminars where teachers across various districts exchange their experience and teaching methods. This could help to introduce the new way of teaching to a wider range of private and public schools in Russia.

For this to succeed, it is vital to educate the faculty on the importance of building dialogue with students. Since many teachers do not show interest in their students as individuals, students mirror their attitude by losing interest in their subject. Adding a personal dimension to teaching can cause a significant improvement in the classroom environment. This can be done first by simply asking students their opinions on current events, class materials, or teaching methods and being open and welcoming to their feedback.

It is also important that, from the beginning, teachers keep a growth mindset and see their students as an alternative source of knowledge. Teachers need to believe that they learn along with and from students and that they can make mistakes too. For example, students can be given creative freedom to solve problems in their own way instead of strictly following a given pattern, as long as it achieves the result.

This leads me to another point-equality. In SaP practice, faculty and students have equal though differing roles. For developing more fulfilling relationships with students, 
faculty members need to learn how to treat their students as equals, in the sense of valuing them as important contributors to educational dynamics. Only when that power is given to students can they feel free to express their opinions and start learning for the sake of learning and not out of fear of failing.

After these basic concepts are applied, institutions might consider moving further. "Softer" SaP approaches may be introduced first, before trialing a more structured SaP practice such as a pedagogical student consultant program.

\section{CONCLUSION}

At its core, the Faculty-Student Partnership Program is designed to build bridges between the faculty and the student body and transform the education system. However, in doing so, it also transforms the mindsets of people who are involved in it. This experience changed the way I looked at the teaching profession and ignited a desire to further my studies and pursue a career in academia. It taught me some valuable skills that I am able to utilize at my job at the university today. On the other side, partnering professors witnessed their classrooms being transformed into open spaces for dialogue and more stimulating environments, with students being more engaged and learning more effectively, further increasing their interest and motivation. Being a graduate now, I can only hope that the new generation of students can benefit from the FSPP in the same way-not only in Hong Kong but in the rest of the world as well, especially in the countries where the gap between faculty and students is still very wide. As for me, I am determined to be a part of a similar program in the future and even run one when I am a teacher myself.

The Faculty-Student Partnership Program was most recently funded by Teaching Development Grant \#102472 from Lingnan University Hong Kong. This paper conforms to the Research Ethics guidelines of the institution.

\section{ACKNOWLEDGEMENTS}

I would like to give special thanks to Julie Groves for her selfless guidance within and outside the program, and to express my gratitude to Prof Preet Hiradhar for her continued support.

\section{NOTES}

1. The program was originally called the Student Consultant Program.

\section{NOTE ON CONTRIBUTOR}

Polina Vandysheva has a degree in marketing and international business from Lingnan University Hong Kong where she also worked as a student partner from 2018-2020. She is currently working for Lingnan as a visiting English tutor while studying a master's degree in international management at the University of Birmingham, UK. 


\section{REFERENCES}

Bindra, G., Easwaran, K., Firasta, L., Hirsch, M., Kapoor, A., Sosnowski, A., Stec-Marksman, T., \& Vatansever, G. (2018). Increasing representation and equity in students as partners initiatives. International Journal for Students as Partners, 2(2), 10-15. https://doi.org/10.15173/ijsap.v2i2.3536

Matthews, K. E. (2017). Five propositions for genuine students as partners practice. International Journal for Students as Partners, 1(2). https://doi.org/10.15173/ijsap.v1i2.3315

Pounder, J. S., Ho, E. H. L, \& Groves, J. M. (2016). Faculty-student engagement in teaching observation and assessment: A Hong Kong initiative. Assessment \& Evaluation in Higher Education, 41(8), 1193-1205.

https://www.tandfonline.com/doi/full/10.1080/02602938.2015.1071779 